\title{
Assessment of attitude towards use of emergency contraceptives among antenatal women
}

\section{Nirmala Jaget Lakkawar*, Shally Magon, Padma Alaganandam}

Department of Obstetrics \& Gynaecology, Sri Lakshmi Narayana Institute of Medical Sciences (SLIMS), Bharath University, Pondicherry-605009, India

Received: 22 October 2014

Accepted: 1 November 2014

\section{*Correspondence:}

Dr. Nirmala Jaget Lakkawar,

E-mail: drnirmalajaget@yahoo.com

Copyright: ( $)$ the author(s), publisher and licensee Medip Academy. This is an open-access article distributed under the terms of the Creative Commons Attribution Non-Commercial License, which permits unrestricted non-commercial use, distribution, and reproduction in any medium, provided the original work is properly cited.

\begin{abstract}
Background: Despite the wide availability of a range of modern contraceptives, unwanted and unplanned pregnancies continue to be a major problem in most of the developing countries like India. Situations such as unprotected sex, improper use of regular contraceptives, failure of barrier methods and sexual violence often lead to an unwanted pregnancy, which may warrant for unsafe abortions. Introduction of Emergency Contraception (EC) over the counter in India in the recent past can help women to avoid unintended pregnancies.

Methods: The present cross sectional study was designed to assess the awareness, level of knowledge and usage of EC among the women attending antenatal clinic. Systematic random sampling was used to select the participants for the study. 200 married women in age group between 18-35 years were interviewed through a pretested structured questionnaire to collect information on age, education, residential and socioeconomic status, obstetric profile, knowledge and usage of EC.

Results: The average age of women included in the study was 24.2 years \pm 4.2 . The knowledge and usage of EC among the participants was $11.5 \%$ and $10.5 \%$ respectively. Age, education, socio-economic status, religion and parity had the significant role in knowledge and attitude towards EC. Clinician and electronic media were the most important source of information about EC. Knowledge about the brand name, time frame for usage and the side effects of EC were known to $60.8 \%, 43.4 \%$ and $17.9 \%$ of the participants respectively. Chemist and general practitioners were the first choice of places for obtaining the EC.

Conclusions: Most importantly, the women who are most likely to need EC and those who are at high risk of an unintended pregnancy but not using any method of contraception have low level of knowledge about emergency contraception. There is a need for sustained efforts by the government and non-government organization including the media to clarify the difference between emergency contraception and medical abortion in order to increase acceptability and willingness to use emergency contraceptive measures.
\end{abstract}

Keywords: Emergency contraception, Awareness, Practice, Antenatal

\section{INTRODUCTION}

The ability of women to control their own fertility is absolutely fundamental to women's empowerment and equality. Unintended pregnancy is a public health issue that warrants the attention of healthcare professionals and policy decision-makers. ${ }^{1,2}$ Determining the causes of these pregnancies and identifying methods to prevent them has the potential to greatly improve the health of women and their children. An unintended pregnancy may result in morbidity and socio-economic challenges for the patient, the infant, and the families involved. ${ }^{3} \mathrm{~A}$ woman with an unintended pregnancy may experience domestic violence, suffer from depression, receive late prenatal care, and unwittingly expose the fetus to teratogens. ${ }^{2-5}$ Furthermore, an unintended pregnancy may cause one or both parents to alter their plans in pursuing an education with subsequent economic consequences. ${ }^{3}$ Adverse fetal 
outcomes associated with unintended pregnancy include low birth weight, neonatal death, child neglect, and abuse $^{6}$.

Every year, women throughout the world have 75 million unwanted pregnancies. Globally, between 120 and 165 million women want to limit or delay future pregnancies, but are not using contraception. ${ }^{7}$ In India, the contraceptive prevalence rate is 56 percent $^{8}$. The recent National Family Health Survey shows that $9 \%$ of all recent births or pregnancies were not wanted and $12 \%$ of women would have preferred to delay the pregnancy. ${ }^{9,10}$ Emergency Contraception (EC) is defined as therapy used to protect against pregnancy after an unprotected or inadequately protected sexual intercourse. Several methods are used for this purpose namely hormonal, which should be used within 72 hours of an unprotected intercourse, or Mechanical like insertion of copper-T, which is recommended within 5 days of unprotected intercourse.

The Emergency Contraceptive (EC) pill has been approved as Over The Counter (OTC) by Government of India, since 2005. Depending on the method used, emergency contraception can reduce a women's risk of becoming pregnant from a single act of intercourse by $75 \%$ to $99 \% .^{11}$ Though, WHO recommended EC as safe, convenient and effective method of contraception, but it is not widely accepted and utilised by the women in reproductive age group in various parts of India.

Hence, this study was conducted in antenatal women to assess the knowledge and attitude towards the usage of emergency contraception at Sri Lakshmi Narayana Institute of Medical Science (SLIMS), Kudapakkam, Pondicherry, India.

\section{METHODS}

A prospective cross sectional study was carried out on 200 married women in antenatal women in age group between 18-35 years attending antenatal clinic of Sri Lakshmi Narayana Institute of Medical Sciences (SLIMS), Bharath University, Pondicherry-605009, India employing systematic random sampling method.

All the patients willing to participate, falling into selected age group were included in the study. Unmarried women and participants not willing to participate were excluded from the study. Interview of the participants on individual basis was conducted orally on the structured preformed and pretested questionnaire, which was developed to cover the research objectives. Ethical requirements of informed consent and confidentiality were ensured. No incentives of any kind were offered to the participants. Ethical approval was obtained from the institutional ethics committee prior to the start of the study.

The questionnaire included information about age, education, residence, occupation, obstetric profile, parity, knowledge and usage of EC. Women who had knowledge regarding $\mathrm{EC}$ were further questioned about the source of knowledge, names of various methods, time of use, whether EC was practiced in the past or not, side effects (if any) and success rate of EC earlier used.

The data collected were analysed using SPSS version 20 for percentage, proportions, chi square test and significance of associations at the level of $\mathrm{P} \leq 0.05$ and $\leq 0.01$.

\section{RESULTS}

In the present study, 200 antenatal women were interviewed through a preformed questionnaire aged between 18-35 years, with an average age of $24.2 \pm 4.2$ years. The knowledge and usage of EC among the participants was $11.5 \%$ and $10.5 \%$ respectively. There was significantly higher awareness $(\mathrm{P} \leq 0.05)$ and usage $(\mathrm{P} \leq 0.01)$ about EC in women aged more than 25 years (Table 1, 2).

The level of education of the participants was found to be significantly associated $(\mathrm{P} \leq 0.01)$ with the level of knowledge and usage of EC. The knowledge (80\%) and practice $(60 \%)$ was highest among the subjects with higher education (University degree) and the participants educated less than middle school had almost no knowledge $(1.28 \%)$ of EC. The urban residents had comparatively higher knowledge and usage of EC in comparison to rural participants. Significantly lower (P $\leq 0.01)$ awareness $(6.8 \%)$ and use $(6.1 \%)$ of EC was observed in participants of lower socio-economic status in comparison to middle and upper class (Table 1,2).

Awareness and use of contraceptives were significantly higher $(\mathrm{P} \leq 0.01)$ in Hindu and Christian (11-12\%) participants in comparison to Muslims, wherein the knowledge and usage was only 7.63 and $8 \%$ respectively. Primi-gravida patients had shown significantly higher knowledge $(18 \%)$ and usage $(16.6 \%)$ of EC in comparison to multigravida wherein, $7.8 \%$ had awareness and $7 \%$ reported usage of EC (Table 1,2 ).

The main source of information regarding the EC was through clinicians, television, friends and relatives, and internet followed by health care providers, chemists and family planning clinics. Most of the participants obtained the information on EC from multiple sources (Figure 1).

Table 3 depicts that chemist (100\%) and general practitioners $(100 \%)$ were the first choice of places for obtaining the EC as compared to Government hospitals $(21.7 \%)$.

Among all the participants having the knowledge of EC, $60.8 \%$ were aware of the names, $43.4 \%$ were aware of the time frame for the usage and $17.9 \%$ were aware of the side effects of emergency contraceptives (Table 4). 
Table 1: Relationship between socio-demographic factors and knowledge regarding emergency contraception $(n=200)$.

\begin{tabular}{|c|c|c|c|c|c|c|c|}
\hline \multirow{3}{*}{$\begin{array}{l}\text { Socio-demographic } \\
\text { factors }\end{array}$} & \multirow{3}{*}{ Number } & \multirow{3}{*}{ Percent } & \multicolumn{4}{|c|}{ Knowledge of emergency contraception $(\mathrm{n}=\mathbf{2 3})$} & \multirow{3}{*}{$P$ value } \\
\hline & & & \multicolumn{2}{|c|}{ Yes } & \multicolumn{2}{|c|}{ No } & \\
\hline & & & Number & Percent & Number & Percent & \\
\hline \multicolumn{8}{|l|}{ Age } \\
\hline $18-25$ & 132 & 66 & 13 & 9.8 & 119 & 80.2 & \multirow{2}{*}{0.039} \\
\hline $26-35$ & 68 & 34 & 10 & 14.7 & 58 & 85.3 & \\
\hline \multicolumn{8}{|l|}{ Education } \\
\hline Illiterate & 2 & 1 & 0 & 0 & 2 & 100 & \multirow{4}{*}{0.000} \\
\hline Up to middle school & 78 & 39 & 1 & 1.28 & 77 & 98.7 & \\
\hline Up to High school & 110 & 55 & 14 & 12.7 & 96 & 87.3 & \\
\hline University degree & 10 & 5 & 8 & 80 & 2 & 20 & \\
\hline \multicolumn{8}{|l|}{ Residence } \\
\hline Rural & 142 & 71 & 7 & 4.92 & 135 & 95.08 & \multirow{2}{*}{0.000} \\
\hline Urban & 58 & 29 & 16 & 27.5 & 42 & 72.5 & \\
\hline \multicolumn{8}{|l|}{ Socio-economic status } \\
\hline Lower & 147 & 73.5 & 10 & 6.8 & 137 & 93.2 & \multirow{3}{*}{0.028} \\
\hline Middle & 52 & 26 & 12 & 23 & 40 & 77 & \\
\hline Upper & 1 & 0.5 & 1 & 100 & 0 & 0 & \\
\hline \multicolumn{8}{|l|}{ Religion } \\
\hline Hindu & 120 & 60 & 15 & 12.5 & 105 & 87.5 & \multirow{3}{*}{0.00} \\
\hline Muslim & 26 & 13 & 2 & 7.6 & 24 & 92.4 & \\
\hline Christian & 54 & 27 & 6 & 11.1 & 48 & 88.9 & \\
\hline \multicolumn{8}{|l|}{ Obstetrics history } \\
\hline Primi-gravida & 72 & 36 & 13 & 18 & 59 & 82 & \multirow{2}{*}{0.041} \\
\hline Multi-gravida & 128 & 64 & 10 & 7.8 & 118 & 92.2 & \\
\hline
\end{tabular}

Table 2: Relationship between socio-demographic factors and practice regarding emergency contraception $(\mathrm{n}=200)$.

\begin{tabular}{|c|c|c|c|c|c|c|c|}
\hline \multirow{3}{*}{$\begin{array}{l}\text { Socio-demographic } \\
\text { factors }\end{array}$} & \multirow{3}{*}{ Number } & \multirow{3}{*}{ Percent } & \multicolumn{4}{|c|}{ Practice of emergency contraception $(n=21)$} & \multirow{3}{*}{ P value } \\
\hline & & & \multicolumn{2}{|c|}{ Yes } & \multicolumn{2}{|c|}{ No } & \\
\hline & & & Number & Percent & Number & Percent & \\
\hline \multicolumn{8}{|l|}{ Age } \\
\hline $18-25$ & 132 & 66 & 13 & 9.8 & 119 & 91.2 & 0.000 \\
\hline $26-35$ & 68 & 34 & 8 & 11.7 & 60 & 88.3 & \\
\hline \multicolumn{8}{|l|}{ Education } \\
\hline Illiterate & 2 & 1 & 0 & 0 & 2 & 100 & 0.000 \\
\hline Up to middle school & 78 & 39 & 0 & 0 & 0 & 0 & \\
\hline Up to High school & 110 & 55 & 15 & 13.6 & 95 & 86.4 & \\
\hline University degree & 10 & 5 & 6 & 60 & 4 & 40 & \\
\hline \multicolumn{8}{|l|}{ Residence } \\
\hline Rural & 142 & 71 & 6 & 4.2 & 136 & 95.8 & 0.000 \\
\hline Urban & 58 & 29 & 15 & 9.4 & 43 & 90.6 & \\
\hline \multicolumn{8}{|c|}{ Socio-economic status } \\
\hline Lower & 147 & 73.5 & 9 & 6.1 & 138 & 93.9 & 0.031 \\
\hline Middle & 52 & 26 & 11 & 21.1 & 41 & 78.9 & \\
\hline Upper & 1 & 0.5 & 1 & 100 & 0 & & \\
\hline \multicolumn{8}{|l|}{ Religion } \\
\hline Hindu & 120 & 60 & 14 & 11.6 & 106 & 88.4 & 0.000 \\
\hline Muslim & 26 & 13 & 1 & 3.8 & 25 & 96.2 & \\
\hline Christian & 54 & 27 & 6 & 11.1 & 48 & 88.9 & \\
\hline \multicolumn{8}{|l|}{ Obstetrics history } \\
\hline Primi-gravida & 72 & 36 & 12 & 16.6 & 60 & 83.4 & 0.041 \\
\hline Multi-gravida & 128 & 64 & 9 & 7 & 119 & 93 & \\
\hline
\end{tabular}




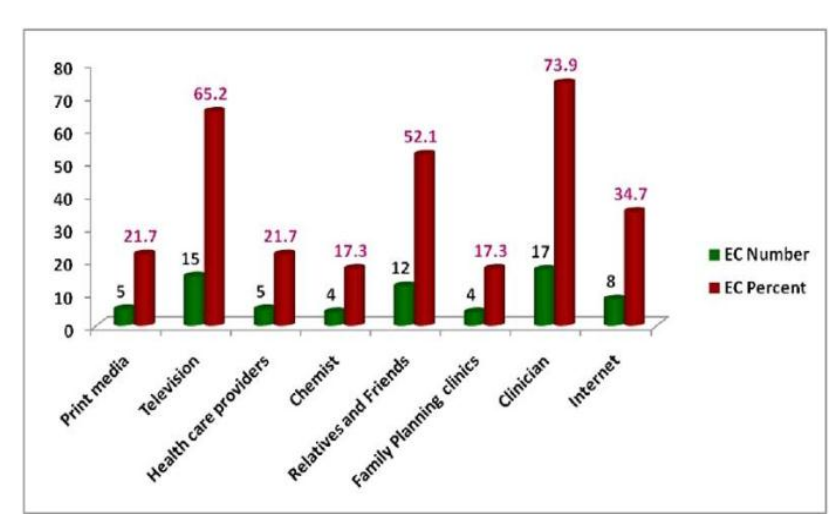

Figure 1: Source* of information regarding emergency contraception.

*Most of the participants received information regarding emergency contraception through multiple sources

Table 3: Knowledge of names, dosage and timing of emergency contraceptives.

\begin{tabular}{|l|llll|}
\multirow{2}{*}{ Knowledge } & \multicolumn{4}{l}{ Emergency contraceptives } \\
& Yes & & No \\
\cline { 2 - 5 } & Number & Percent & Number & Percent \\
\hline Names & 14 & 60.8 & 9 & 39.2 \\
\hline Dosage & 0 & 0 & 23 & 100 \\
\hline Timing & 10 & 43.4 & 13 & 56.6 \\
\hline
\end{tabular}

Table 4: Place* of availability of emergency contraceptives.

\begin{tabular}{|lll|}
\hline \multirow{2}{*}{ Source* } & \multicolumn{2}{l}{ Emergency contraceptives } \\
\hline Chemist & Number & Percent \\
\hline Private medical practitioner & 23 & 100 \\
\hline Government hospitals & 23 & 100 \\
\hline
\end{tabular}

* Most of the participants received information regarding emergency contraception through multiple sources

\section{DISCUSSION}

A lot of awareness is being generated for the temporary and permanent methods of contraception since the inception of family planning programme in India in 1952. However, unprotected, unplanned exposure and contraceptive accidents like forgotten pills, condom burst and slipping of diaphragm lead to failure of contraception and unwanted pregnancy leading to high rate of abortions in India. ${ }^{11}$

Emergency contraception or post-coital contraception prevents unwanted pregnancy following unprotected sexual intercourse and failure of regular contraception. ${ }^{12}$ Hence, this study was conducted to evaluate the knowledge and attitude towards the use of emergency contraceptives in women attending antenatal clinic.
Though the national contraceptive prevalence rate is $56 \%$, the knowledge about the EC is only $20 \%$ in men and $11 \%$ in women. ${ }^{8}$ In our study, the awareness about EC was among $11.5 \%$ of the participants.

Studies conducted earlier in different parts of India reported almost similar awareness of $10.46 \%$ in Aurangabad, Maharashtra, ${ }^{13} 12.67 \%$ in Mumbai, Maharashtra, ${ }^{14} 7.3 \%$, in Chandigarh. ${ }^{15}$

A study conducted at Ahmadabad, India revealed higher knowledge (44\%) about EC among the medical and allied health science students in comparison to (15\%) among the non-medical discipline including engineering students. ${ }^{16}$

Similar study conducted at Bangalore, India revealed $24.2 \%$ of the participants were aware about EC and television commercials were the major source of knowledge for $64.22 \%$ in the study group. ${ }^{17}$

Literacy has an important role to enable women to accesses any information. Education benefits the participants to possess the ability to understand awareness and promotion of contraception through print, electronic media, posters and brochures. In the present study, the knowledge and usage of EC was associated with the level of education. Participants with University degree were most informed about the availability and usage of EC. Participants from the urban areas and belonging to middle and upper class revealed more awareness and higher usage of EC in comparison to rural residents and women from lower socioeconomic strata.

Similar finding of better educated women being more informed about the EC has also reported in earlier studies. $^{13,18}$

Study conducted among the post-partum and post-abortal women at tertiary care hospital, Varanasi, India reported significant association between socioeconomic status and contraceptive usage. EC was known to $20 \%$ of the participants studied. ${ }^{19}$

A similar study among the antenatal women at medical college hospital, Kolkata, West Bengal also reported awareness of EC among $20 \%$ participants was proportional to the level of education, wherein $69 \%$ were educated high school and above. ${ }^{20}$

Women from rural areas are comparatively less aware about emergency contraceptives in comparison to urban residents, ${ }^{13}$ which can be attributed to lower educational, socio-economic status and less access to the information and benefits of contraceptives among the rural population.

A similar significant association was found between contraceptive acceptance and literacy status, occupation, type of family, socioeconomic status in married women in reproductive age group. ${ }^{19,21}$ 
In the present study, participants belonging to Hindu and Christian community had comparatively higher awareness and usages of contraception in comparison to Muslim women. However, this difference may be due to smaller representation by the community in the present study population.

A study conducted to assess the knowledge and practice of contraception among the women in Mangalore, Karnataka revealed that Christians followed contraception the most then the Hindus and Muslims. ${ }^{22}$

Out of the 124 Muslim subjects studied, only 34 (27.4\%) were found using contraceptives suggesting that IEC activities needs to be strengthened in Muslim community as $90(72.6 \%)$ were not using any of the temporary or permanent contraceptives. ${ }^{23}$ In a study conducted in Dehradun, India ${ }^{24}$ and Mewat, India ${ }^{25}$ reported low use of contraception, which can be associated with younger age of the women, illiteracy rate and Muslim religion. However, no influence of religion on contraceptive usage had also been reported. ${ }^{26}$

In the present study, awareness and usage of EC was more reported by primigravida in comparison to multigravida participants. This difference may be because most of the primigravida in the study were educated and belonged to urban areas.

Most of the subjects in the present study reported clinician, television, relatives and friends, and internet as important source of information on EC. In addition, chemists, family planning clinics, health care providers, magazines and newspapers were helpful in spreading the awareness about emergency contraceptives. Similar observation on media and relatives being the important source of information on contraception has also been reported earlier. ${ }^{13}$ The electronic media followed by newspapers, magazines, doctors, nurses, friends, family and pharmacist are the important source of information on emergency contraceptives. ${ }^{16}$ Most of the studies reported limited role of health care providers other than the clinicians in disseminating the knowledge on EC among the recipient population. ${ }^{13,16,18}$

Most of the participants reported easy accesses to EC at chemist and private medical practitioners in comparison to Government Hospitals corroborating with the earlier finding. ${ }^{13,16}$

In our study, $60.8 \%$ respondents were aware about of names of the EC, but the knowledge on exact timings and side effects of the drugs were comparatively less. Higher awareness $(50 \%)$ of brand name, timings and side effects of EC was reported among the antenatal women in Varanasi, India. ${ }^{16}$

In a study conducted at Chandigarh, India revealed that most of respondents were unaware of the exact time frame for administration of EC and very few had the knowledge of side effects. ${ }^{15}$
Observation from the present study emphasises on need of sustained efforts by the Government health facilities and health care providers towards the awareness of emergency contraceptives. The targeted group should be teenagers, antenatal mothers and the women attending MTP clinics when these women are more receptive for the information. Adequate information on emergency contraceptives should be made available before the actual need arises. The misconceptions about the EC as an abortifacient, and that its use promotes irresponsibility and promiscuous lifestyle should be discouraged.

\section{CONCLUSION}

With the current prevalence of modern contraceptive use, the awareness for the emergency contraceptives is very low in different parts of India. An essential component of providing emergency contraception is informing potential users about this important option before they need it the most. Because the timeframe for seeking treatment is short, women need to be aware that emergency contraception is an option and know where they can seek these services.

Women also need to understand that emergency contraception should be started as soon as possible after an act of unprotected intercourse, but definitely before the required timeframe for both the methods. The side effects of EC are very low compared to the risk associated with carrying an unintended pregnancy and unsafe abortion. There is a significant scope for emergency contraception in India, which needs to be publicized by professional associations, women's health groups, and NGOs to spread awareness and use of emergency contraception.

\section{ACKNOWLEDGEMENTS}

Authors are thankful to Dr. S. Rajasekaran, dean, SLIMS, Pondicherry, India for providing the necessary facilities to carry out the research work and Dr. R. Ganesan, associate professor (Statistics and computer science), department of animal genetics and breeding, RIVER, Pondicherry, India for managing the data for this study.

Funding: No funding sources

Conflict of interest: None declared

Ethical approval: The study was approved by the institutional ethics committee

\section{REFERENCES}

1. Pregnancy Risk Assessment Monitoring System (PRAMS). PRAMS and unintended pregnancy, 2009. Available

at: http://www.cdc.gov/PRAMS/UP.htm. Accessed 10 August 2009.

2. Santelli J, Rochat R, Hatfield-Timajchy K, Gilbert BC, Curtis K, Cabral R, et al. The measurement and 
meaning of unintended pregnancy. Perspect Sex Reprod Health. 2003;35(2):94-101.

3. Brown S, Eisenberg L. The best intentions. In: Brown S, Eisenberg L, eds. Unintended Pregnancy and the Well-Being of Children and Families. Washington (DC): National Academy Press; 1995.

4. Westhoff C. Emergency Contraception. N Engl J Med. 2003;349(19):1830-5.

5. Kuroki LM, Allsworth JE, Redding CA, Blume JD, Peipert JF. Is a previous unplanned pregnancy a risk factor for a subsequent unplanned pregnancy? Am J Obstet Gynaecol. 2008;199(5):517.

6. Payakachat N, Ragland D, Houston C. Impact of emergency contraception status on unintended pregnancy: observational data from a women's health practice. Pharm Pract (Intern). 2010;8(3):1738

7. IIPS. National family health survey-2 (NFHS-2), 1998-99, India, International Institute for Population Sciences, Mumbai, 2000. Available at: dhsprogram.com/pubs/pdf/FRIND2/FRIND2.pdf

8. IIPS. National family health survey-2 (NFHS-3), 2005-06, India, International Institute for Population Sciences, Mumbai, 2007. Available at: dhsprogram.com/pubs/pdf/FRIND3/FRIND3Vol1AndVol2.pdf.

9. Puri C. Emergency contraception. ICMR Bull. 1997;27(3):19-30.

10. Nayyar A. Increasing access to emergency contraception in India. Health Popul Persp Issues. 2000;23(3):123-33.

11. Family Planning Division, Ministry of Health and Family Welfare Government of India. Guidelines for administration of emergency contraceptive pills by health care providers, 2008. Available at: http://mohfw.nic.in/NRHM/FP/ECP_Book_Final.pdf

12. Puri S, Goe N, Sehagal A, Walia D, Mangat C. Emergency contraception in women of slums in Northern India. J Fam Reprod Health. 2009;3:77-82.

13. Kokane AM, Khadilkar HA. Knowledge of emergency contraception in women attending MTP center at rural tertiary care hospital in India. Asian J Pharm Health Sci. 2012;2(2):333-5.

14. Makade KC, Pedhyegurjar M, Pedhyegurjar SB, Kulkarni RN. Study of contraceptive use among married women in a slum in Mumbai. National $\mathbf{J}$ Community Med. 2012;3(1):40-3.

15. Puri S, Bhatia V, Swami HM, Singh A, Sehgal A, Kaur AP. Awareness of emergency contraception among female college students In Chandigarh, India. Indian J Med Sci. 2007;61(6):338-46.
16. Shelat PR, Hihoriya NH, Kumbar S. Knowledge and attitude towards the use of emergency contraceptive pills among college students. Int J Basic Clin Pharmacol. 2012;1(2):77-84.

17. Lakshmidevi M, Venkatesh S, Saxena RK, Pandey P. Knowledge, experience and opinion on emergency contraception among urban educated women. J Evol Med Dent Sci. 2014;34(3):9039-45.

18. Kose V, Joshi S. Knowledge of emergency contraception among married women of reproductive age in a rural based teaching hospital of Nagpur, Maharashtra, India. JSAFOG. 2012;4(2):106-9.

19. Thapa S, Rani A, Mishra CP. Knowledge, attitude and belief about contraception in post-partum and post abortal women in a tertiary care centre. Int $\mathbf{J}$ Reprod Contracept Obstet Gynaecol. 2014 Sep;3(3):533-9.

20. Chakraborty A, Paul J, Mondal P, Saha M, Seth S, Mitra PS, et al. Assessment of knowledge and practice of contraception among antenatal mothers attending antenatal clinics of a newly developed medical college in Kolkata, West Bengal. Int $\mathbf{J}$ Healthcare Biomed Res. 2013;1(4):315-20.

21. Murarkar SK, Soundale SG. Epidemiological correlates of contraceptive prevalence in married women of reproductive age group in rural area. Natl J Community Med. 2011;2(1):78-81.

22. Lakshmi MM, Neetha Rai S. Contraceptive practices among reproductive age group of women in Justice K. S. Hegde medical college hospital, Mangalore. Int J Reprod Contracept Obstet Gynaecol. 2013;2(1):3946.

23. Prateek SS, Saurabh RS. Contraceptive practices adopted by women attending an urban health centre. Afr Health Sci. 2012;12(4):416-21.

24. Chandra RAK, Kandpal SD, Negi KS. Epidemiological correlates of contraceptive prevalence in rural population of Dehradun district. Indian J Community Med. 2005;30(2):60-2.

25. Gaur D, Goel MK, Goel M. Contraceptive practices and related factors among females in predominantly rural Muslim area of North India. Intern J World Health Soc Polit. 2008;5(1):3

26. Pushpa SP, Venkatesh R, Shivaswamy MS. Study of fertility pattern and contraceptive practices in a rural area- a cross sectional study. Indian J Sci Technol. 2011;4:429-31.

DOI: $10.5455 / 2320-1770 . i j r \operatorname{cog} 20141237$

Cite this article as: Lakkawar NJ, Magon S, Alaganandam P. Assessment of attitude towards use of emergency contraceptives among antenatal women. Int J Reprod Contracept Obstet Gynecol 2014;3:1067-72. 